\title{
Incidence and causes of blindness among the under 5 age group in Malawi
}

\author{
D. BENEZRA* AND M. C. CHIRAMBO \\ From the Eye Department, Queen Elizabeth Central Hospital, Blantyre, Malawi
}

SUMMARY The expected incidence of blindness among children under 5 years of age in Malawi is 34 cases per 100000 children. Direct ocular infections were responsible for the blindness in $32 \%$ of the cases (bacterial infections $20 \%$ and measles $12 \%$ ). The instillation of traditional medicine in these cases worsened the ocular condition and induced in all of the cases a 'hopeless' situation of total melting of the cornea and protrusion of the uvea. Congenital factors (excluding retinoblastomas) were responsible for $30.8 \%$ of the blind cases. Among these, 11 cases of congenital cataracts were successfully treated and will not appear as blind in future. A high incidence $(9.3 \%)$ of cortical blindness was recorded. Trauma was implicated in $5.3 \%$, while retinoblastoma was found in $8 \%$.

It is believed that adequate preventive measures should be able to lower the incidence of blindness among this age group to 5 cases instead of 34 per 100000 children.

In a previous paper (Chirambo and BenEzra, 1976) we reported a retrospective study of the causes of blindness among 270 blind students attending 17 blind school institutions in Malawi. It was found that infections as a group were the main cause of blindness, while measles was the most common single cause. At the period when most of these students became blind the prevalence of blindness in Malawi (then Nyasaland) was estimated at $\mathbf{3 0 0}$ to 500 (or more) cases per 100000 inhabitants. These numbers corrected to give the incidence among children are believed to be even higher (Phillips, 1961; Merin, 1967). These data were based mostly on the 'impression' of the ophthalmologist or on a very small pilot study excluding adequate representation of the group of children under 5 years of age, a group with the highest incidence of blindness in developing countries. From our experience, we estimated the incidence of blindness in this age group in the early 1960 s at 400 (or more) blind per 100000 children. The relative contribution of this age group to the evaluation of the prevalence of blindness could not be adequately reflected, as the mortality rate among blind young infants in develop-

*Dr BenEzra is on leave from the Department of Ophthalmology, Hadassah Hebrew University Hospital, Jerusalem, Israel.

This work was supported by the Ministry of Health, Malawi Government, and the Jerusalem Institute for the Prevention of Blindness, Jerusalem, Israel.

Address for reprints: D. BenEzra, MD, Clinical Branch, National Eye Institute, National Institutes of Health, Building 10, Room 10D-09, Bethesda, Maryland 20014, USA. ing countries was very high. Following 10 years of sponsorship of ophthalmological care in Malawi by the department of ophthalmology of the Hadassah Hebrew University of Jerusalem, Israel, a study of the causes and incidence of blindness among the population of children under 5 years of age was undertaken. Adequate statistical evaluation of the population of children in the different districts was available as the consequence of an extensive campaign for the promotion of maternal and child health on a national basis (Malawi Ministry of Health, 1975). To the best of our knowledge this is the first study of the causes and incidence of blindness among the whole child population under 5 in an African country.

\section{Methods}

Malawi is divided into 24 districts. Each district has a district hospital and peripheral dispensaries, the number of which varies according to the density of the population. The dispensaries are run by medical assistants, while the district hospital is in general directed by a medical officer (general practitioner) with the assistance of a clinical officer, medical assistants and nurses. All problematical cases needing specific care are referred to the central hospital in Blantyre. 11 ophthalmic medical assistants (non-graduate) are posted in the most densely populated districts. They deal with routine cases and minor surgery, while all ocular problems and major surgery are referred to the eye department 
in Queen Elizabeth Central Hospital in Blantyre directed by two eye specialists. This system, although not perfect, enables most of the ophthalmic cases to be seen by an ophthalmic medical assistant while problematical cases are referred to the ophthalmologist. Patients selected to be seen by the eye specialist are provided with travel warrants from their home to the central hospital.

It is estimated that some $25 \%$ of all cases needing eye care are seeking traditional treatment (local medicine) or are treated in missionary institutions all over the country. Most of these are also referred to us, especially when the outcome is blindness.

The number of children under 5 years of age among the Malawi population has been estimated at nearly one million (947 900) (Malawi Ministry of Health, 1975).

From 1 June 1975 to 31 November 1975 we have tried to collect all blind cases occurring among the under 5 age group all over the country. To promote accuracy we made frequent trips to the different districts during this period. However, it was quite impossible to visit each and every peripheral dispensary often enough. We feel that a 'true' incidence of blindness has been obtained in only 4 districts of the southern region. These had a population of 205800 children under 5 years of age and were frequently visited by an ophthalmologist.

The criterion for blindness was arbitrarily scored when vision in the better eye was less than perception of familiar domestic objects at a distance of $1 \mathrm{~m}$.

\section{Results}

The mean incidence during the studied period was 12.5 cases per month. The highest number of cases were seen during November (Table 1). 39 cases were boys and 36 were girls, a total of 75 cases in 6 months. Correction of these figures according to the incidence obtained from 4 districts of the Southern Region (Mangochi, Zomba, Chiradzulu, and Blantyre), where nearly every new blind case in this age group was seen and referred, gives a 'true' incidence of more than double the above. From these 4 districts, with a total population of 205800 children under 5 , a yearly incidence of 70 blind children is calculated (Table 2). This incidence can also be expressed as 34 cases per 100000 children.

Table 1 Monthly incidence of blindness during the period of study

\begin{tabular}{lccccccc}
\hline & June & July & August & Sept. & Oct. & Nov. & Total \\
\hline Male & 6 & 6 & 6 & 7 & 6 & 8 & 39 \\
Female & 6 & 5 & 8 & 4 & 5 & 8 & 36 \\
Total & 12 & 11 & 14 & 11 & 11 & 16 & 75 \\
\hline
\end{tabular}

Table 2 Incidence of cases according to districts

\begin{tabular}{|c|c|c|}
\hline District & $\begin{array}{l}\text { Population of } \\
\text { children under } 5 \text { years }\end{array}$ & $\begin{array}{l}\text { Number of } \\
\text { blind cases }\end{array}$ \\
\hline Chitipa & 13,700 & 1 \\
\hline Rumphi & 10,800 & 2 \\
\hline Mzimba & 52,900 & 6 \\
\hline Karonga & 17,900 & - \\
\hline Nkhata Bay & 19,400 & - \\
\hline Total Northern Region & 114,700 & 9 \\
\hline Kasungu & 22,500 & 1 \\
\hline Nkhotakota & 14,500 & - \\
\hline Ntchisi & 15,400 & - \\
\hline Dowa & 42,000 & 2 \\
\hline Salima & 20,000 & 1 \\
\hline Lilongwe & 125,100 & 4 \\
\hline Mchinji & 19,800 & - \\
\hline Dedza & 53,200 & 2 \\
\hline Ncheu & 37,900 & 5 \\
\hline Total Central Region & 350,400 & 15 \\
\hline Mangochi* & 43,700 & 8 \\
\hline Kasupe & 52,000 & 4 \\
\hline Zomba* & 65,100 & 12 \\
\hline Chiradzulu* & 32,700 & 6 \\
\hline Mwanza & 9,700 & - \\
\hline Blantyre* & 64,300 & 9 \\
\hline Thyolo & 57,400 & 5 \\
\hline Mulanje & 91,900 & 3 \\
\hline Chikwawa & 36,500 & 4 \\
\hline Nsanje & 23,800 & - \\
\hline Total Southern Region & 484,800 & 51 \\
\hline
\end{tabular}

*These districts were often visited by the ophthalmologists, and the incidence obtained is believed to be the nearest to the 'true incidence'.

Among the causes of blindness direct ocular infections were found in $32 \%$ of all cases. Bacterial agents were responsible for $20 \%$ of all cases, while sequelae of measles (including superimposed bacterial infections) were the cause of blindness in $12 \%$ of all cases (Table 3 ). If the sequelae of encephalitis were added, the total incidence of blindness due to infections amounted to $38.7 \%$. All the cases of ocular infections leading to blindness were referred at a very advanced stage. In most of these cases traditional medicine had been applied. This superimposed chemical factor resulted in most cases in total melting of the cornea and prolapse of the uvea. Trauma was responsible for $5 \cdot 3 \%$ of the blind cases and retinoblastoma for $8.0 \%$ (Table 3 ). Other than retinoblastomas, 23 blind cases $(30.8 \%)$ were due to a congenital cause. Among these, 11 cases of congenital cataracts were successfully operated. The high incidence of $9.3 \%$ due to cortical blindness is ill understood. Most of these cases were referred to the paediatric ward with a history of fever and severe headaches of 1 to 2 months' duration followed by a sudden blindness. Giant hydrocephalus inducing optic atrophy was responsible for the blindness in 6 cases (Table 3).

\section{Discussion}

When the figures from all 24 districts are considered, it appears that in Malawi there is an annual incidence 
Table 3 Causes of blindness among the 75 cases

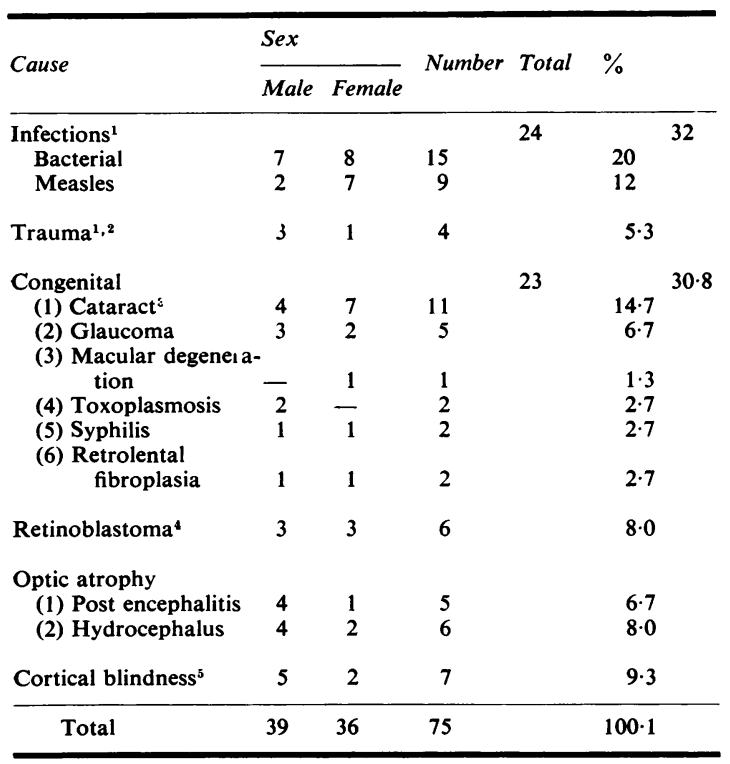

${ }^{1}$ Most of these cases used local medicine and were referred at a late stage. In all cases we failed to retain useful vision.

${ }^{2}$ Only in 2 cases the bilateral involvement was due to trauma. In 2 others 1 eye was previously blind due to infection.

'These cases were operated and will not appear in future as 'blind'. 'Only 4 cases were blind due to bilateral retinoblastoma. One case had a blind eye due to trauma and the other with retinoblastoma. In another case the fellow eye was blind owing to infection.

${ }^{5}$ In these cases the cause of blindness could not be defined accurately as anterior and posterior segments appeared normal.

of 15 blind cases per 100000 children under 5 years. This is obviously an underestimate as in many districts, especially those far from Blantyre, the registration probably did not reflect the real incidence. A figure of 34 blind cases per 100000 was obtained from the 4 districts where referral and registration of cases were optimal. If $21.4 \%$ of these are excluded as the result of successful cataract or trabecular operation, a yearly incidence of 27 blind children per 100000 children under 5 is to be recorded. This incidence is nearer to the 'true' incidence over the country. If previous estimates are considered accurate, the incidence of blindness among children in Malawi as shown by this study has dropped during the last 10 years by 80 to $90 \%$. This progress could be achieved only by the provision of a high standard of ophthalmological care throughout the country along with education (Michaelson, 1972). However, compared to the incidence of 3.8 blind cases per 100000 children under 5 as found in most developed countries (Great Britain, 1968 to 1969; National Eye Institute, 1971), an incidence of 27 cases per 100000 children is still 7 times higher than it need be. We believe the main causes of the disparity are the still widely used instillation of traditional medicine for the treatment of ocular infections and the deferment of medical consultation until an advanced stage of the disease. During 197515 cases of severe ophthalmia neonatarum and 32 cases of severe keratoconjunctivitis in children under 5 were admitted to the department in Blantyre. None of these used traditional medicine. As a result of treatment vision was restored in all cases. On the other hand useful vision was not restored in any of the cases that were referred after the use of traditional medicine and all of them remained blind.

Thirty-two per cent of the blindness was due to a direct ocular infection. This is a relatively low figure as compared to the data from a retrospective study demonstrating the frequency of infection as a cause of blindness in $75.2 \%$ of the cases (Chirambo and BenEzra, 1976). The incidence of $32 \%$ of blindness in Malawi due to direct ocular infection, although much lower than in the early 1960 s and lower than the incidence in other African countries (Awdry et al., 1967; Olurin, 1970), is nevertheless much higher than the figures reported from more developed countries (Merin et al., 1972; Baghdassarian and Tabbara, 1975). This comparison indicates how much remains to be done in the prevention of blindness among children in Malawi.

An extensive campaign of education through the health services and schools directed toward eradication of the instillation of traditional medicines for the treatment of ocular infections, early referral, prevention of trauma, adequate surgical measures, and a better understanding of the pathology in some cases - for example, of cortical blindnessshould be able to reduce considerably the incidence of blindness among young children in Malawi. A conjoint programme of the health and ophthalmology services aiming to reach a figure of 5 blind cases per 100000 children within the period of 5 years is being established and will be further reported.

We thank Professor I. C. Michaelson, director of the Jerusalem Institute for the Prevention of Blindness, for his support and advice. Our thanks are due also to Mrs Sapao, head nurse of the department of ophthalmology, Queen Elizabeth Central Hospital, Blantyre, Malawi, and to $\mathrm{Mr}$ Buniani, clinical officer, ophthalmic assistant, in charge of the eye unit, Zomba Central Hospital, for their valuable help during this study.

\section{References}

Awdry, P. N., Cobb, B., and Adams, P. C. G. (1967). Blindness in the Luapula Valley. Central African Journal of Medicine, 13, 197-201. 
Baghdassarian, S. A., and Tabbara, K. F. (1975). Childhood blindness in Lebanon. American Journal of Ophthalmology, 79, 827-830.

Chirambo, M. C., and BenEzra, D. (1976). Causes of blindness among students in blind school institutions in a developing country. British Journal of Ophthalmology, 60, $665-668$.

Great Britain, Department of Health and Social Security (1968-69) Report on the State of the Public Health for 1967-68 (2 volumes). London, HMSO.

Malawi Ministry of Health, Medical Statistic Unit (1975). Statistical Report on Maternal and Child Health Activities.

Merin, S. (1967). Malnutrition as a cause of blindness in children. Malawi Medical Bulletin, 2, 6-8.
Merin, S., Lapithis, A. G., Horowitz, D., and Michaelson, I. C. (1972). Childhood blindness in Cyprus. American Journal of Ophthalmology, 74, 538-542.

Michaelson, I. C. (1972). Causes and Prevention of Blindness, pp. 57-58. New York and London, Academic Press.

National Eye Institute (1971). Statistics on Blindness in the Model Reporting Area, 1968. Public Health Service Publication. Washington, DC Government Printing Office.

Olurin, O. (1970). Etiology of blindness in Nigerian children. American Journal of Ophthalmology, 70, 533-540.

Phillips, C. M. (1961). Blindness in Africans in Northern Rhodesia. Central African Journal of Medicine, 7, 153-158. 